\title{
KNOWLEDGE TOWARDS PREVENTION OF CERVICAL CANCER AMONG NURSING STUDENTS OF ANMTC BARH, BIHAR
}

\author{
Mrs. Samapti Pal* | Dr. Jogindra Vati**
}

*Ph.D. Scholar, Himalayan University, Itanagar, Arunachal Pradesh, India \& Nursing Tutor, IGIMS College of Nursing, Patna, Bihar, India. ** Research Guide at Himalayan University, Itanagar, Arunachal Pradesh, India. DOI: http://doi.org/10.47211/idcij.2021.v08i01.010

\section{ABSTRACT:}

Cervical cancer is the most common cancer among Indian women. Numerous studies were conducted on Nursing students towards the prevention of cervical cancer in India and all over the world. Previous studies disclosed there is a lack of knowledge regarding cervical cancer among nursing students. In this study, ANM students were selected as ANM are working in the community and are the first-line health care provider according to the Indian health care system. Therefore, the study to assess the knowledge of ANM students towards the prevention of cervical cancer is done.

Purpose: the purpose of the study was to assess the knowledge towards the prevention of cervical cancer among nursing students and to find an association between knowledge and selected demographic variables.

Methodology: A non-experimental descriptive study was conducted to assess knowledge towards the prevention of cervical cancer among 111 nursing students of ANMTC Barh, Bihar. The age group was 17-22 years. Both $1^{\text {st }}$ and $2^{\text {nd }}$-year students, whoever was available during the data collection and willing were included in the study. A self-structured questionnaire was developed for assessing the level of knowledge among nursing students. The tool was found valid and reliable after testing. A purposive sampling technique was selected. The collected data were tabulated and analyzed by using descriptive and inferential statistics.

Result: The majority of the students belonged to age 19 years (32.4\%), almost $93.7 \%$ of students were Hindu. The main source of information was mass media (32.4\%). Although a majority of the students (56\%) were having average knowledge, the highest level of knowledge was present among 21 years age group and the lowest was present among 22 years of age group.

Conclusion: The study showed that being health care providers also a majority of the students are having average knowledge towards prevention of cervical cancer which raises a concern, as preventive measures are to be spread through the health care providers themselves. So, it is recommended to conduct more studies in this regard and to plan for an awareness program.

Key words: cervical cancer, health care providers, ANMTC Barh, Bihar.

\section{ABOUT AUTHORS:}

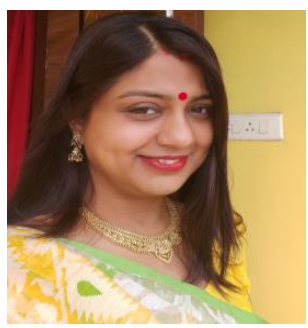

Author Mrs. Samapti Pal, is Ph.D. Research Scholar in Himalayan University, Arunachal Pradesh, India.

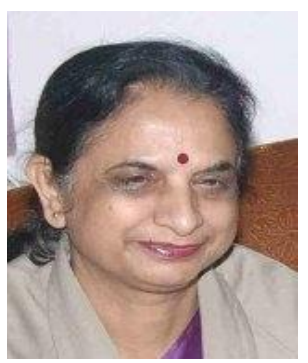

Author Dr. Jogindra Vati is Research Supervisor in Himalayan University, Arunachal Pradesh, India. 


\section{INTRODUCTION:}

"Cervical cancer" is secondary vaginal malignancy by direct spread. Major factors affecting the prevalence of carcinoma cervix in a population are an economic factor, sexual behaviors, and degree of effective screening. ${ }^{1}$

The worldwide incidence of cervical cancer in 2018, an estimated 570000women were diagnosed with cervical cancer worldwide and we loss about 311000 women. if diagnosed, cervical cancer is one of the most efficaciously treatable forms of cancer, as long as it is spotted early and treated effectively. ${ }^{2}$ cervical cancer ranks as athe $2^{\text {nd }}$ most frequent cancer among women berween 15 and 44 years of age in India. In 201896922 women are detected with cervical cancer and 60078 die from the disease. ${ }^{3}$

There are numerous risk factors for cervical cancer. First intercourse at a younger age, multiple sex partners, cigarette smoking, race, high parity, and lower socioeconomic status. Evidence has proved that screening through pap smear can radically reduce the chance of getting the disease but, due to lack of knowledge among community people, the demand for screening is not there. Recent developments like, HPV vaccination if taken before the person becomes sexually active would offer greater protection. ${ }^{3}$

Several studies have proved there is a lack of knowledge among nursing students towards cervical cancer. Nurses need to take up the responsibility to create awareness among women to improve their knowledge and motivate them to undergo pap smear tests for early detection and educate them regarding lifestyle modifications and the availability of a vaccine to prevent the disease, especially when we are considering ANM. ANM is working in the community exclusively, so they are having the opportunity to influence the community as a public health worker. Thus, the knowledge of the ANM students is taken into consideration for this study.

Research approach \& Design: Quantitative non-experimental approach and design.

Setting: ANM Training Center, Barh, Bihar

Inclusion criteria and exclusion criteria: All the students of ANMTC Barh and who were available and willing to participate in the study.

Sample and sampling technique: Simple purposive Sampling technique was adopted.

Selection and development of tool: 1. Socio-demographic profile like education, religion, socioeconomic status, source of information was included.

2. Knowledge questionnaire to assess knowledge. The tool was self-structured with a total of 24 questions. All were multiple-choice question-answers. 1 mark for each correct answer was provided.

Ethical permission: Ethical permission has been taken from the HOD of the institution.

RESULT:

The results show that regarding age the distribution was a majority of the students belonged to 19 years of age group $32.4 \%$ and only 3 students were at the age of 22 years. Related to religion, the maximum number of students were from the Hindu religion $93.7 \%$ whereas $6.3 \%$ students were Muslims. No other religion was found during the study participants. 99.1\% ANM students were having an education of 10+2, only 1 student was having a degree of B.Sc. $32.4 \%$ of students got information about cervical cancer from Mass Media. Books and teachers are also shown as a good source for information related to the disease, $27.9 \%$, and $22.5 \%$ respectively. Others, $17.1 \%$ came to know about it from friends and neighbors.

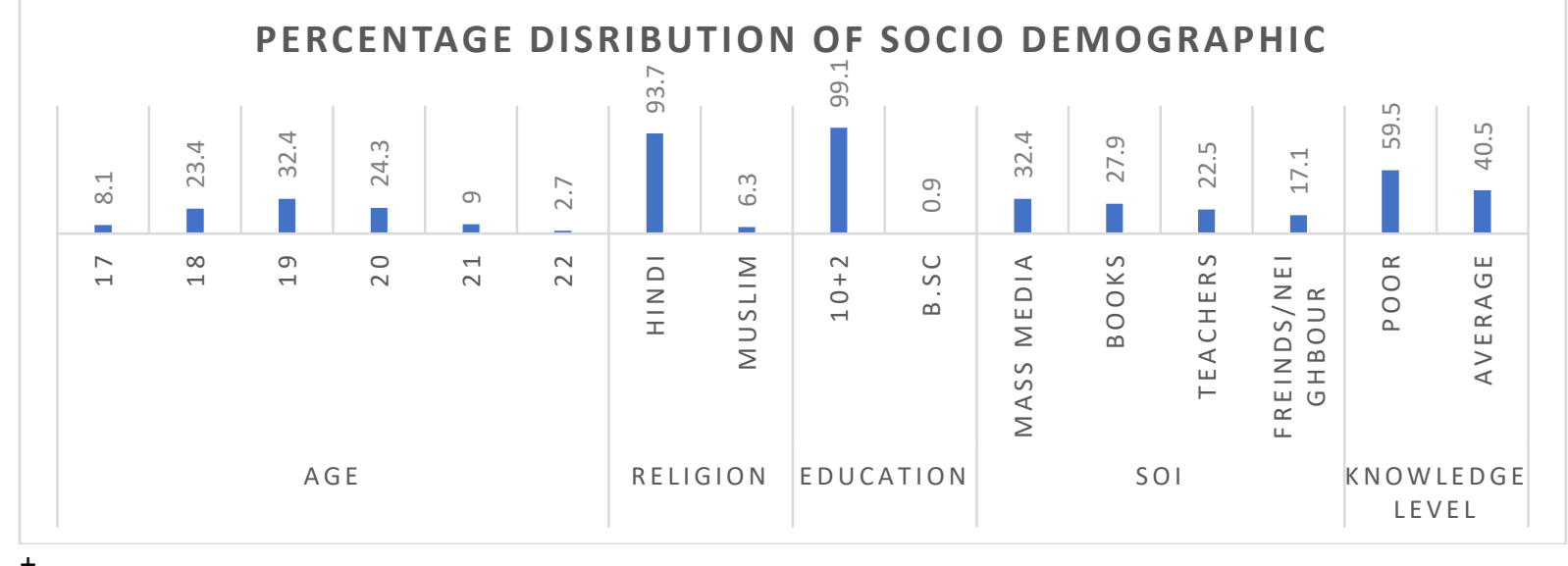

The collected data shows out of 111 ANM students $59.5 \%$ of students had poor knowledge towards prevention of cervical cancer, and $40.5 \%$ of students had average knowledge. None of the students had good knowledge towards the prevention of cervical cancer which raises the concern. 


\begin{tabular}{|c|c|c|}
\hline Level of Knowledge & & \\
\hline Poor (0-8) & 66 & 59.5 \\
\hline Average (8-16) & 45 & 40.5 \\
\hline
\end{tabular}

When comparing the age with a level of knowledge among the students, the age group pf 17 years the mean score was $(10.33 \pm 3.94)$, concerning age group of 18 years the mean score was $(10.81 \pm 4.38)$, regarding age group 19 years the mean score was $(10.62 \pm 3.57)$, the mean score regarding age group 20 years was $(9.87 \pm$ $3.58)$ the mean score of 21 years age group was $(11.80 \pm 4.54)$ and the mean score regarding age group of 22 years was $(9.33 \pm 2.89)$. Thus, the highest level of knowledge was present among the 21 year age group and the lowest level of knowledge was present mong 22 years of age group.

Regarding religion, the distribution shows concerning Hindu nursing students the mean score $(10.36 \pm 3.86)$ and for the Muslim nursing students, the mean score was (12.71 \pm 2.81$)$. considering education, the distribution shows that for $10+2$ nursing students the mean score was $(10.53 \pm 3.85)$, for the only B.Sc. student the mean score was 11.00 \pm .

It is noted that regarding the source of information, the distribution shows that concerning mas media, the mean score was $(10.63 \pm 3.87)$, for books, the mean score was $(10.44 \pm 4.26)$, for teachers, the mean score was $(10.82 \pm 3.78)$ and concerning neighbors/friends the mean score was $(10.13 \pm 3.34)$.

Statistically, a significant association has been found between religion and level of knowledge at $5 \%$ level of significance, whereas all other age, education, source of information were statistically not significant concerning the level of knowledge.

\begin{tabular}{|c|c|c|c|c|c|}
\hline \multirow[b]{2}{*}{ Age } & & \multicolumn{4}{|c|}{$N=111$} \\
\hline & & In years & $N$ & Mean & Std Deviation \\
\hline \multirow{10}{*}{$\begin{array}{l}\text { Source } \\
\text { Information }\end{array}$} & \multirow{10}{*}{ of } & 17 & 9 & 10.33 & 3.94 \\
\hline & & 18 & 26 & 10.81 & 4.38 \\
\hline & & 19 & 36 & 10.62 & 3.57 \\
\hline & & 20 & 27 & 9.87 & 3.58 \\
\hline & & 21 & 10 & 11.80 & 4.54 \\
\hline & & 22 & 3 & 9.33 & 2.89 \\
\hline & & Mass media & 32 & 10.63 & 3.87 \\
\hline & & Books & 25 & 10.44 & 4.26 \\
\hline & & Teachers & 22 & 10.82 & 3.78 \\
\hline & & Friends/neighbours & 16 & 10.13 & 3.44 \\
\hline
\end{tabular}

\section{DISCUSSION:}

According to the study findings, the maximum number of nursing students were in the age group of 19 years, which is opposed by the study done by Gandhi Ramya ${ }^{4}$ et al, where the majority of the respondents belonged to 20-21 years of age group. Concerning religion, the distribution shows that $92.63 \%$ of the nursing students were Hindu and $7.37 \%$ were Muslim concluding majority of the students were Hindu, no other religion was found. This is supported by the study done by Josephine Jacqueline Mary ${ }^{5}$ et all in which the majority of the respondents were Hindu. As the distribution shows that $98.95 \%$ of nursing students were $10+2$ and the remaining $1.05 \%$ were B.Sc. thus it can be interpreted that the highest percentage of education was $10+2$. Higher education level was not found among the students during the study. These findings were supported by Krishnaveni $\mathrm{K}^{6}$ et al where they also found the majority of the respondents had higher secondary education. Regarding the source of information, the distribution shows that the mass media was the source of information for $32.4 \%$ of the nursing students followed by books and teachers 27.9 and 22.5 respectively. A study done by Narayan $\mathrm{G}^{7}$ et all supports these findings as in the study the main source of information was media (41.6\%).

Study findings show among 111 nursing students $59.5 \%$ of students were having poor knowledge and $40.5 \%$ of students were having average knowledge towards the prevention of cervical cancer. Unfortunately, none of the students were having good knowledge among the study participants, the study is contrasting by the study done by Mulatu Kebadnew ${ }^{8}$ et all, where it was found that students with good, average and poor level of knowledge was $25.36 \%, 40.67 \%$, and $33.97 \%$ respectively.

In keeping with the study findings highest level of knowledge was 21 years age group and the lowest was 22 years age group, this is reinforced by the study done by Kalayu, Birhane Mruts ${ }^{9}$ et all, where it was found the highest level of knowledge was among the age group of 20-24 years. Regarding education, the distribution 
shows that for $10+2$ students the mean score was $(10.53+3.85)$ with respect to B.Sc. the mean score was $(11.00 \pm)$. These findings were supported by Awosan J Kehinde ${ }^{10}$ et all, who found that the proportion of respondents with good knowledge of cervical cancer was significantly higher among the respondents that had higher secondary or tertiary education (17.5\%) as compared to primary education (7.9\%). Concerning the source of information, the distribution shows that with respect to mass media, the mean score was (10.63 \pm 3.87), followed by books and teachers. These findings were supported by Kalayu Birhane Mruts ${ }^{9}$, et all found that respondents who were using radio and TV as their source of information were almost 2 times more likely to have good knowledge on the prevention of cervical cancer than those who did not use media. Statistical significance was found between religion and level of knowledge

\section{CONCLUSION:}

The study showed that being health care providers also the majority of the students are having average knowledge towards the prevention of cervical cancer which raises a concern, as preventive measures are to be spread through the health care providers themselves. Specifically by the ANMs, who are working side by side in the community. So, it is recommended to conduct more studies in this regard and to plan for an awareness program.

\section{REFERENCE:}

1. Text book of Gynecology including contraception, D.C.Dutta, 2018,327-340.

2. https://www.who.int/health-topics/cervical-cancer\#tab=tab_1

3. https://hpvcentre.net/statistics/reports/IND_FS.pdf

4. Kaarthigeyan K Cervical cancer in India and HPV vaccination, Indian Journal Of Medicine Paediatric Oncology, 2012, p. 7-12.

5. Partha Basu \& Debjani Chowdhury, Cervical cancer screening \& HPV vaccination: a comprehensive approach to cervical cancer control, Indian Journal Medical Resources, 2009, p. 241-246.

6. Gandhi Ramya, Nitya Selvaraj, Ilamparithi Janarthanam, Knoledge and Attitudeof Cervical Cancer Screening and its Prophylactic Vaccination against Human Papillomavirus among the Undergraduate Medical Students in a Tertiary Care Hospital, Annals of Pathology and Laboratory Medicine, Vol. 5, 2018, p. A-516-A-520.

7. Josephine Jacquline Mary NI, et al. Effectiveness of a Structured Teaching Programme on Knowledge Regarding Cervical Cancer among Women in Selected Wards of Malampuzha Panchayat at Palakkad District, Kerala. Nurs Health Care Int J 2019, 3(2): 000182.

8. Krishnaveni K, Roy $\mathrm{P}$ and Sambathkumar R: Knowledge, attitude and practice related to cervical cancer and screening among women: community based cross - sectional study. Int J Pharm Sci Res 2018; 9(2):722-29. doi: 10.13040/IJPSR.0975-8232.9(2).722-29.

9. G Narayana, M. Jyoti Suchitra, G Sunanda, J Dasaratha Ramaiah, B Pradeep Kumar, KV Veerabhadrappa, Knoledge, Attitude and Practice Towards Cervical Cancer among womenattending Obstetrics and Gynecology Department,South India,Indian Journal of Cancer, 2017, Vol - 54,- 2- 481487

10. Mulatu K, Motma A, Seid M, et al. Assessment of Knowledge, Attitude and Pratice on Cervical Cancer Screening among Female Students of Mizan Tepi University, Ethiopia, 2016. Cancer Biology and Therapeutic Oncology. 2017, Vol 1, p - 1-6

11. Mruts Kalayu Brhane, Gebremariam Tesfay, Knowledge and Perception Towards Cervical Cancer among Female Debre Berhan University Students, July 2018, Asian Pacific Journal of Cancer Prevention 19(7):1771-1777

12. Gana GJ, Oche MO, Ango JT, Kaoje AU, Awosan KJ, Raji IA. Educational intervention on knowledge of cervical cancer and uptake of Pap smear test among market women in Niger State, Nigeria. J Public Health Afr. 2017 Dec 31;8(2):575. doi: 10.4081/jphia.2017.575. PMID: 29416840; PMCID: PMC5793045. 